\title{
Invited review: Inbreeding in the genomics era: Inbreeding, inbreeding depression, and management of genomic variability
}

\author{
Jeremy T. Howard, ${ }^{* 1}$ Jennie E. Pryce, $¥ \ddagger$ Christine Baes,§ and Christian Maltecca*\# \\ *Department of Animal Science, North Carolina State University, Raleigh 27695-7627 \\ †Agriculture Victoria, Agribio, 5 Ring Road, Bundoora 3083, Australia \\ łLa Trobe University, Bundoora, Victoria 3086, Australia \\ §Centre for Genetic Improvement of Livestock, Department of Animal Biosciences, University of Guelph, 50 Stone Road E., Guelph N1G 2W1, \\ Canada \\ \#Genetics Program, North Carolina State University, Raleigh 27695-7627
}

\section{ABSTRACT}

Traditionally, pedigree-based relationship coefficients have been used to manage the inbreeding and degree of inbreeding depression that exists within a population. The widespread incorporation of genomic information in dairy cattle genetic evaluations allows for the opportunity to develop and implement methods to manage populations at the genomic level. As a result, the realized proportion of the genome that 2 individuals share can be more accurately estimated instead of using pedigree information to estimate the expected proportion of shared alleles. Furthermore, genomic information allows genome-wide relationship or inbreeding estimates to be augmented to characterize relationships for specific regions of the genome. Region-specific stretches can be used to more effectively manage areas of low genetic diversity or areas that, when homozygous, result in reduced performance across economically important traits. The use of region-specific metrics should allow breeders to more precisely manage the trade-off between the genetic value of the progeny and undesirable side effects associated with inbreeding. Methods tailored toward more effectively identifying regions affected by inbreeding and their associated use to manage the genome at the herd level, however, still need to be developed. We have reviewed topics related to inbreeding, measures of relatedness, genetic diversity and methods to manage populations at the genomic level, and we discuss future challenges related to managing populations through implementing genomic methods at the herd and population levels.

Key words: inbreeding, genomics

Received February 22, 2017.

Accepted April 25, 2017.

${ }^{1}$ Corresponding author: jthoward@ncsu.edu

\section{INTRODUCTION}

Characterizing and efficiently managing inbreeding levels has been, and will continue to be, an important goal in dairy cattle-breeding programs to ensure that populations can adapt to future breeding goals while maintaining genetic diversity and avoiding the accumulation of detrimental effects associated with inbreeding. The use of genomic information as a tool to cost-effectively predict breeding values, referred to as genomic selection (Meuwissen et al., 2001), has dramatically changed dairy cattle breeding (Hayes et al., 2009). Because of genomic selection, an increasing number of selection candidates across both sexes are currently routinely genotyped. For example, the number of genotyped Holstein animals in the United States exceeds 1 million animals (https://www.uscdcb.com/Genotype/ cur_ctry.html). The advent of genomic selection has reduced the generation interval and increased the selection intensity, which has dramatically increased the rate of genetic gain, especially for lowly heritable traits (García-Ruiz et al., 2016). Genomic information has shifted the landscape on how candidates are selected, although we argue that a similar degree of change has yet to be seen in the utilization of genomic information to manage dairy populations. Annual rates of genetic gain of US Holstein females assessed using the net merit selection index have nearly doubled for cows born since 2010 (approximately when genomically tested sires became widely used) compared with the previous decade (https://www.uscdcb.com/eval/summary/trend.cfm).

As shown by Miglior and Beavers (2014), the introduction of genomic selection has resulted in a more diverse set of bulls sampled for testing, yet the number of bulls siring $50 \%$ of the young bulls entering AI has remained relatively constant. Thus, although a more diverse set of bulls are screened, this is not translating into more genomically diverse bulls being offered to breeders.

In general, the majority of methods to manage a population and its associated effective population size are related to the coancestry among the parents used to 
obtain the next generation, while taking into account the expected genetic value of the progeny (Kristensen and Sorensen, 2005). Prior to genomic information, pedigree relationships were used to manage inbreeding within a population (VanRaden and Smith, 1999). However, pedigree information is based on the expected proportion of the genome that is identical by descent (IBD) between 2 parents and thus does not capture the variation due to Mendelian sampling and linkage during gamete formation (Franklin, 1977; Hill, 1993; Guo, 1996; Hill and Weir, 2011). Genomic information allows an estimate of the realized proportion of the genome that 2 individuals share, either genome-wide, or at specific regions (Hill and Weir, 2011). The implications of this difference will be discussed throughout the paper.

The use of region-specific metrics that characterize the genetic diversity (i.e., effective population size) and inbreeding depression at specific regions can be used along with commonly estimated genome-wide metrics. Thus, the matings of a sire with potential dams with similar coancestry values at the genome-wide level might be further discriminated on the basis of haplotypic diversity within low-diversity regions. This is expected to have an effect on the genomic load carried by the resulting offspring. The use of region-specific metrics should allow breeders to more effectively manage the risks associated with sire or mate selection, allowing one to better evaluate the trade-off between the genetic value of the progeny and undesirable side effects associated with inbreeding. Last, as time progresses, a larger number of new factors will come into play during sire or mate selection. The inclusion of dominance effects (Sun et al., 2013), the exploitation of variation in recombination across the genome (Ma et al., 2015), the increase in use of advanced reproductive technologies (Ponsart et al., 2013), and introduction in the future of gene-editing procedures, among others, will affect the management of genomic diversity, both at the population as well as the farm level. Research on how to manage genetic resources based on all these factors simultaneously, rather than individually, should be a top priority.

In this paper, we review the current state and future challenges related to inbreeding, measures of relatedness, genetic diversity, and methods to manage populations at the genomic level. In the last section, we discuss the challenges of managing inbreeding at the individual herd level and future areas of research.

\section{INBREEDING}

The mating of related individuals is unavoidable in populations of finite sizes, as the number of ancestors increases exponentially per generation. The inbreeding coefficient of an individual is defined as the probability of 2 randomly chosen alleles, at the same locus from 2 gametes, which unite to be IBD from a common ancestor (Crow and Kimura, 1970). Another consequence of finite populations is the random fluctuation of gene frequencies (i.e., genetic drift) and the eventual loss of alleles due to the sampling process during gamete formation (Falconer and Mackay, 1996). Inbreeding leads to changes in the distribution of genetic variance, leading to allelic fixation and, in principle, reducing the additive genetic variance within a population as well as decreasing the rate of response to selection for a trait under selection and other traits (Kristensen and Sorensen, 2005). The nonadditive (i.e., dominance and epistatic) proportion of the genetic variance is highest at intermediate frequencies and, similar to the additive genetic variation, as alleles become fixed due to inbreeding the nonadditive variance also decreases. It should be noted though that, in principle, the genetic variance is expected to decrease across the long-term horizon, whereas within the short-term horizon it is possible for the additive genetic variance to increase as a result of nonadditive effects being converted to additive effects (Kristensen and Sorensen, 2005). Furthermore, increased levels of inbreeding result in a reduction in the mean value of a trait, referred to as inbreeding depression, which has been documented across all livestock species (reviewed by Leroy, 2014). Within dairy populations, the accumulation of inbreeding is unavoidable due to several factors. A few of these include multiple generations of intense directional selection (Robertson, 2007), high variance of reproductive success across individuals due to the use of advanced reproductive technologies (Nicholas and Smith, 1983), and the use of BLUP-based genetic evaluations in combination with truncation selection (Verrier et al., 1993). These processes lead to the widespread use of related individuals as parents of the next generation. The extent of inbreeding depression depends on allele frequencies and the strength of directional selection; therefore, it is expected to be population specific, as drift and selection pressure vary across populations. Lastly, fitness traits, such as survival, reproduction, and disease resistance, are more affected by inbreeding. It is thought that fitness traits exhibit a greater degree of directional dominance than traits distantly related to fitness (i.e., type traits or adult body size; Kristensen and Sorensen, 2005).

\section{The Genetic Basis of Inbreeding Depression}

Changes due to inbreeding on the phenotypic mean of a trait at $n$ biallelic loci, and assuming no epistasis, can be estimated as 


$$
2 F \sum_{i=1}^{n} p_{i} q_{i} d_{i}
$$

where $F$ is the inbreeding coefficient as described previously, $p_{i}$ and $q_{i}$ are allele frequencies and $d_{i}$ is the dominance deviation at the $i$ th locus (Crow and Kimura, 1970). Therefore, inbreeding depression will only be observed if the trait is affected by dominance. Inbreeding depression is explained by 2 main hypotheses. The partial dominance hypothesis assumes that inbreeding depression is caused by the expression of deleterious recessive alleles in homozygous individuals. As inbreeding accrues within a population, the frequency of deleterious recessive homozygotes, which were initially hidden in heterozygotes, increases and exposes the deleterious effect. Alternatively, the over-dominance hypothesis refers to dominance effects displaying heterozygote advantage and, as inbreeding accrues, the number of heterozygous genotypes is reduced and the superior heterozygote genotypes are less frequent (Crow and Kimura, 1970). Both hypotheses have similar underlying mechanisms related to the degree of dominance at loci, but their long-term implications are different. For the over-dominance hypothesis, selection would favor heterozygote states at multiple loci, and therefore mutations would be maintained by mechanisms related to balancing selection. Under the partial dominance hypothesis, selection would purge unfavorable alleles generated by mutations over time within a population (Kristensen and Sorensen, 2005). In both cases, loci with intermediate frequencies are expected to contribute more to inbreeding depression than loci with extreme frequencies (Kristensen and Sorensen, 2005). Purging of inbreeding depression is a process whereby inbred animals with good performance have been selected to become parents from the population, whereas the poorly performing inbred animals have been culled or do not survive to breeding age; purging of inbreeding depression has been shown to occur in dairy populations (Gulisija et al., 2007; Mc Parland et al., 2009). Purging regresses the estimate of inbreeding depression toward zero when estimated as a function of inbreeding on performance, because homozygosity in some regions of the genome is no longer unfavorable (Boakes et al., 2007). It has been shown that slow inbreeding accumulation results in more efficient selection against deleterious recessive mutations than strong inbreeding (Hedrick, 1994; $\mathrm{Fu}$ et al., 1998). In general, partial dominance is thought to account for a large proportion of the inbreeding depression observed in livestock, plant, and natural populations (Charlesworth and Charlesworth, 1987). Inbreeding depression can also be generated by epistasis between dominance effects across loci, such that favorable gene combinations among heterozygous genotypes decrease in frequency during the inbreeding process (Jain and Allard, 1966). Under the first 2 hypotheses, in the absence of epistasis inbreeding depression is a linear function of the inbreeding level. When epistasis occurs, inbreeding depression is expected to be a nonlinear function of the inbreeding level; although the assumption that nonlinearity of inbreeding implies epistasis can be heavily confounded by several other factors, as described by Lynch and Walsh (1998), and remains difficult to prove in most circumstances.

\section{Determining the Effect of Inbreeding Based on Pedigree Information}

Prior to genetic marker information becoming available, the effect of inbreeding on economically important traits was investigated by regressing the phenotype of interest on the inbreeding value using pedigree information. According to this method, inbreeding depression has been shown to exist across many traits of economic importance in dairy cattle, such as milk production (Miglior et al., 1995; Thompson et al., 2000a,b), age at first calving (Smith et al., 1998), calving interval (Pryce et al., 2014), and longevity metrics (Thompson et al., 2000a,b; Sewalem et al., 2006). The common assumption for these estimates of inbreeding depression is that inbreeding depression is a linear function of the inbreeding level of an individual. However, some studies have shown nonlinear inbreeding depression, and a faster rate of depression is seen at higher levels of inbreeding (Thompson et al., 2000b; a; Wall et al., 2005; Gulisija et al., 2007). Also, genome-wide inbreeding metrics do not account for the fact that homozygosity at some regions might, in principle, be more detrimental than other regions. Consequently, 2 individuals with the same genome-wide inbreeding value could differ in load they carry, resulting in inbreeding to be heterogeneous. This can be seen as an animal's deviation from the regression line of its inbreeding level on the phenotype. One way of investigating heterogeneous inbreeding is to construct founder-specific partial coefficients for each founder within a population using pedigree data instead of overall individual inbreeding (Lacy et al., 1996).The partial inbreeding coefficient for an individual attributed to a given founder measures the probability that an individual is IBD for an allele descended from the specified founder (Lacy et al., 1996). Heterogeneous inbreeding depression has been observed in dairy cattle (Miglior et al., 1994; Gulisija and Crow, 2007; Mc Parland et al., 2009), although in these cases analyses were conducted using pedigree information so that heterogeneity of inbreeding could point to both different genomic load at equivalent inbreeding, but also to a different overall genomic load 
of the founders unidentified by pedigree information. Regardless, heterogeneous inbreeding depression across founders implies that inbreeding derived from a given founder is not necessarily always unfavorable based on the zero or positive inbreeding regression coefficient for a given founder.

As described previously, inbreeding increases the frequency of homozygous loci and, as a result, several lethal recessive mutations have been observed in dairy cattle populations. Lethal recessive mutations have often been discovered from reports of abnormal calves; subsequent breeding trials were then used to confirm the inheritance pattern and manage carriers in the population (VanRaden et al., 2011a). Furthermore, genetic defects visible at birth are easier to study than are those causing death earlier in gestation. Nonetheless, several major recessive defects affecting embryo or fetal survival have been identified and include deficiency of uridine monophosphate synthase (Shanks and Robinson, 1989), bovine leukocyte adhesion deficiency (Shuster et al., 1992), and complex vertebral malformation (Agerholm et al., 2001). Even with very large sets of phenotypic and pedigree data, defects that cause embryo death are difficult to detect without genomic data as a result of the limited number of carrier by carrier matings (VanRaden and Miller, 2006). Thus, a sufficient carrier frequency is required to detect lethal mutations and then methods can be applied to identify carrier animals and the causative mutation.

\section{Methods to Determine the Effect of Inbreeding Based on Genomic Information}

The use of pedigree information to understand inbreeding depression is severely limited, as it relies on genome-wide expected inbreeding estimates. In addition, pedigree information frequently contains parentage errors. Parentage confirmation utilizing genomic information has shown that the frequency of misidentified sires can be as high as 13.9\% (Wiggans et al., 2012). Variation in sharing IBD over the genome, as a result of Mendelian sampling, depends on the pedigree relationship and the extent to which alleles at different loci are jointly IBD (Hill and Weir, 2011). As outlined by Hill and Weir (2011), the variance of realized relationships falls as individuals become more distant, although its coefficient of variation rises. Furthermore, marker information allows for genomic estimates of inbreeding to be altered to allow for the possibility of testing whether the unfavorable inbreeding effect is distributed evenly across the genome. Thus, a more precise estimate of inbreeding, identification of lethal recessive mutations and identification of homozygous regions of the genome that cause reduced phenotypic performance could be exploited in breeding programs.

The regression of performance on genomic estimates of inbreeding have been conducted, and unfavorable estimates per $1 \%$ increase in genomic-based inbreeding have been found; these are generally comparable or slightly larger than pedigree-based estimates (Bjelland et al., 2013; Pryce et al., 2014). A study by Pryce et al. (2014) estimated the regression coefficient on a subset of recently born animals that had both pedigree and genomic information for multiple traits across Australian Jersey and Holstein cows. Across both breeds the $\log P$-values for genomic-based estimates of inbreeding (averaged across breeds and traits $=7.0$ ) were higher for yield traits in comparison to pedigree inbreeding estimates (averaged across breeds and traits $=0.92$ ). The higher $\log P$-value associated with genomic estimates illustrates the benefits of having a more precise inbreeding estimate and not being dependent on pedigree depth. However, the genotyped cows in Pryce et al. (2014) were a subset of all animals available with pedigree information regardless of the genomic content across breeds and traits. When all animals with pedigree-based inbreeding were used, the mean $\log P$-value was 22.65. Differences in the regression coefficients were also observed using all animals with pedigree information and more recently born animals with pedigree and genomic information. Thus, it can be imagined that the relationship between the parental coancestries, or expected progeny inbreeding and the offspring performance, is heavily dependent on the inbreeding depression genetic architecture in the parental population. Consequently the regression coefficient varies across populations and is also heterogeneous across generations within a population.

Genomic information has led to a renewed interest in estimation of dominance effects to improve our understanding of the genetic architecture of inbreeding depression and to estimate inbreeding losses more precisely (Toro and Varona, 2010). Before molecular data, dominance was rarely included in genetic evaluations because large-scale data sets that have a high proportion of full-sib relationships were required, leading to a greatly increased level of computational complexity (Misztal et al., 1998). Estimates of the proportion of total variance due to dominance have generally been low, ranging from 0 to $7 \%$, across a variety of traits and species (Su et al., 2012; Sun et al., 2013; Aliloo et al., 2016; Heidaritabar et al., 2016). More importantly, the ability to predict the phenotype more accurately with the inclusion of dominance across traits and species generally results in very little improvement compared with predictions based on the additive genotypic value 
of an individual (Su et al., 2012; Ertl et al., 2014; Sun et al., 2014; Aliloo et al., 2016; Lopes et al., 2016). The small improvement observed when dominance effects are included has multiple reasons. Weir (2008) and Zhu et al. (2015) illustrated that the proportion of the genetic variance at a causal variant that is captured by markers is $\rho^{2}(\rho=$ correlation between SNP and causal variant) for additive variance and $\rho^{4}$ for dominance variance. Thus, a greater degree of linkage disequilibrium $(\mathbf{L D})$ is required between the causal variant and SNP for dominance effects. Furthermore, independence between additive and dominance effects is the classical treatment (Falconer and Mackay, 1996), and it is convenient because it allows the additive and dominance estimates to be orthogonal. However, this independence contradicts the phenomena of inbreeding depression and hybrid vigor, indicating that dominance is directional (Lynch and Walsh, 1998). Results from real data (Wellmann and Bennewitz, 2011, 2012) support a priori dependency between additive and dominance effects. In addition, given the directionality of dominance, the a priori dominance effect of a gene should be positive, which is a potential reason why fitting the inbreeding coefficient as demonstrated by Xiang et al. (2016) and Aliloo et al. (2017) accounts for directional dominance.

An alternative method to identify IBD segments of the genome that decrease performance has been proposed (Pryce et al., 2014; Howard et al., 2015a; Saura et al., 2015). The same approach has been used to identify disease inducing mutations based on homozygosity mapping (Keller et al., 2012; Wang et al., 2013). The IBD status of a chromosome segment cannot be observed directly, but the IBS status of a chromosome segment can be observed based on multiple successive markers. When 2 chromosome segments occur in the same individual, this is an unbroken run of homozygosity (ROH; MacLeod et al., 2009). The lengths of ROH segments from a common ancestor are expected to follow an exponential distribution with mean $100 / 2 \mathrm{~g} \times \mathrm{cM}$, where $\mathrm{g}$ is the number of generations since the last common ancestor (Fisher, 1954). Assuming $1 \mathrm{cM}=1 \mathrm{Mb}$, a $\mathrm{ROH}$ of length 25,10 , and $2.5 \mathrm{Mb}$ long is expected to come from a common ancestor occurring 2 (4 meiosis), 5 (10 meiosis), and 20 (40 meiosis) generations ago, respectively. Across multiple dairy populations, the frequency of ROH across the genome is not uniform, such that some regions have a high $\mathrm{ROH}$ frequency whereas other regions have a low $\mathrm{ROH}$ frequency (Purfield et al., 2012; Howard et al., 2015b). Intense selection along with a low effective population size has resulted in a high frequency of long homozygous segments (Kim et al., 2013). Kim et al. (2013) found that selection within a dairy population has increased overall autozygosity across the genome, whereas the autozygosity in an un- selected line has not changed significantly across most of the chromosomes.

The results of a simulation by Keller et al. (2011) have shown that ROH-based inbreeding metrics have a higher association with the recessive mutation load compared with pedigree or SNP-by-SNP-based inbreeding metrics. Furthermore, the power of detecting inbreeding depression using $\mathrm{ROH}$-based inbreeding metrics in a randomly breeding population with an effective population size of 100 (similar to dairy cattle), is adequate ( $80 \%$ statistical power) with a sample size of 700 individuals (Keller et al., 2011). It has been found across humans and cattle that $\mathrm{ROH}$ are enriched with deleterious variants, although the length at which the highest frequency of deleterious mutations occurs is shorter in cattle than in humans (Szpiech et al., 2013; Zhang et al., 2015). The increased incidence of deleterious variants within long $\mathrm{ROH}$ stems from the fact that $\mathrm{ROH}$ consist of rare IBD haplotypes that combine at a low frequency and that low-frequency variants are more likely to be deleterious than common variants. For example, consider a rare deleterious variant with frequency $p$ in a population. If the deleterious homozygote genotype occurs in a non-IBD region, the probability of it occurring would be $p^{2}$ under Hardy-Weinberg equilibrium. Alternatively, if the homozygote genotype variant occurred in an IBD region, the probability of it occurring would be $p$, which exceeds the non-IBD probability. Thus, it is expected that $\mathrm{ROH}$ accumulates deleterious homozygosity at a faster rate than regions outside of ROH (Szpiech et al., 2013).

The introduction of routine genotyping for males, and more importantly females, allows for an increased understanding of the genetic architecture of inbreeding depression in dairy populations by allowing identification of genomic regions that negatively affect economically important traits. One challenge in identifying functional inbreeding is that the underlying regions or variants are, for the most part, carried in the population at a low frequency. Additionally, the LD between low-frequency variants and common variants commonly used in SNP chips is greatly reduced. Thus, most methods tailored toward common variants may not be as effective in identifying low-frequency unfavorable variants or segments. Several methods to identify rare variants have recently been developed (Zhang et al., 2016), although their use in livestock populations has not received much attention to date. Zhang et al. (2016) showed that by combining multiple rare variants within a gene there was greater power to map rare variants compared with traditional single-marker regression analysis.

Other methods that use genome-wide scans to search for haplotypes that cause a reduced performance are 
commonly employed. An approach that identifies lethal haplotypes based on genotype data from live animals was described by VanRaden et al. (2011a). Using genotypes from live animals, the method searches for chromosomal regions that contain haplotypes common in the population but absent in the homozygous state (VanRaden et al., 2011a; Sahana et al., 2013). Five lethal haplotypes were identified by VanRaden et al. (2011a) that had unfavorable effects on conception rate, ranging from -3.0 to -3.7 percentage points. The carrier frequencies for the majority of the haplotypes identified were at a low frequency $(<10 \%)$, such that they would have most likely not been identified before the generation of large genotype databases. Additionally, nonlethal unfavorable haplotypes contained within a $\mathrm{ROH}$ have been identified in dairy cattle (Pryce et al., 2014; Howard et al., 2015a). A limitation of using ROH-based metrics to identify unfavorable regions is that a region shown to be sensitive to long stretches of homozygosity may contain multiple unique $\mathrm{ROH}$ genotypes with variable effects on the phenotype of interest. Therefore, the regions need to be investigated further to determine which unique $\mathrm{ROH}$ genotypes(s) result in a reduced phenotype.

The identification of unfavorable haplotypes and their simultaneous use in mating programs to minimize inbreeding depression holds great promise for animal breeding plans. Yet, a need exists to develop efficient methods to identify unfavorable homozygous regions due to inbreeding, which we refer to as an inbreeding footprint. The undesirable regions identified can be incorporated in mating designs to reduce their probability of appearing in the progeny. An approach similar to that of Cole (2015), which weights each haplotype by its probability and economic loss, can be easily extended to include nonlethal haplotypes and thus provide a measure of the functional inbreeding. Also, inbreeding depression is likely to occur across all traits in a breeding objective, although the degree at which inbreeding depression affects each trait is expected to vary across traits. Thus, an index approach, similar to the concept proposed by Segelke et al. (2014), can be used to weight a hypothetical functional inbreeding metric across multiple traits by its overall economic importance. Within this context, to more effectively select replacement females in a dairy herd, the genetic load associated with unfavorable or lethal haplotypes related to culling for fertility, disease, and low production should be investigated. At the current time, the methods discussed are not able to identify a large proportion of regions of the genome that result in reduced performance. Although, as time progresses, larger data sets will become available, which potentially allow for new or previously discussed methods to more effectively identify inbreeding footprints across the genome. Therefore, traditionally used genome-wide relationship information will continue to play an important role in breeding programs to minimize the frequency of unidentified unfavorable IBD regions.

\section{MEASURES OF RELATEDNESS}

As outlined previously, inbreeding refers to mating of parents who share 1 or more ancestors. The concept of relatedness and its implications on inbreeding depression within a population have traditionally had a preeminent role in the management of the genetic diversity of a population. Measures of relatedness within and across individuals have been a key concept in conservation, population, and quantitative genetics, along with breeding. The thinking behind coancestry coefficients, that make them useful across a wide range of disciplines, is that individuals who share DNA at a locus relevant to a phenotype will show a degree of similarity for that phenotype. Therefore, any character that has a genetic component can use coancestry coefficients to better understand the genetic architecture of the trait and its relationship to the genetic diversity of a genome.

Before using molecular information, the expected relatedness, referred to as the coancestry coefficient, was estimated using pedigree information (Falconer and Mackay, 1996). The coancestry coefficient is defined as the probability that 2 neutral alleles drawn at random from a locus, 1 from each of 2 individuals, are descended from the same ancestral allele or are IBD. Thus, the inbreeding coefficient of the offspring is equal to the coancestry coefficient between the parents (Malécot, 1948) and methods to manage inbreeding are all based on this premise. An alternative measure of relatedness referred to as the coefficient of relationship is the correlation between the genetic values of the uniting gametes, developed by Wright (1922). For 2 noninbred individuals and under the assumption of only additive gene action, the coefficient of relationship [i.e., additive numerator relationship matrix (A)] is exactly twice the coancestry coefficient. Multiple computationally efficient methods have been developed to construct $\mathbf{A}$ and its inverse from pedigree information (Meuwissen and Luo, 1992; Colleau, 2002) for millions of animals at a very low computational cost. Similar to $\mathbf{A}$, methods have also been developed to a generate dominance relationship matrix (D), which represents the probability that 2 individuals have the same pair of alleles in common (Cockerham, 1954).

Multiple methods have been developed to generate similarity [i.e., identical-by-state (IBS)]-based genomic relationship metrics $(\mathbf{G})$ derived from marker infor- 
mation (Leutenegger et al., 2003; Amin et al., 2007; VanRaden, 2008; Yang et al., 2010). These methods vary according to the weight that each marker gets in the final $\mathbf{G}$ matrix. The use of a differential weighting across markers is due to the variation in information content across markers. The differing levels of information content are in part due to their differences in allele frequencies within the population and whether that marker is in LD with a QTL or is a QTL. For example, the weighting method described by VanRaden (2008) results in rare alleles receiving a higher weight in $\mathbf{G}$ than common alleles. One drawback of utilizing all markers in constructing $\mathbf{G}$ is that it implies that all markers contribute to genetic variation for a given trait under the context of predicting breeding values. Therefore, as an alternative, methods that weight relationships by their expected variance, effect, or statistical significance from a prior analysis have been developed (Leutenegger et al., 2003; Amin et al., 2007; Zhang et al., 2010; de Los Campos et al., 2013; Tiezzi and Maltecca, 2015). Methods to efficiently construct G have been developed (Aguilar et al., 2011), although computationally they do not scale to a large number of animals as effectively as pedigree-based methods.

Construction of $\mathbf{G}$ assumes that the markers are independent, and thus the location in relation to another marker, or correlation with another marker due to $\mathrm{LD}$, is ignored. Therefore, if the order of a SNP is shuffled when creating $\mathbf{G}$, the relationship matrix will be the same as the unshuffled version. As a result, the G matrix does not fully account for the fact that markers on the same homologous chromosome are inherited together unless a recombination event occurs between them (Gomez-Raya et al., 2015). Furthermore, whereas relationships in pedigree beyond the third generation contribute marginally to variation in overall inbreeding, they do contribute substantially to variation in IBD segments (Stam, 1980). An alternative way of constructing relationships is to determine the IBD probability of chromosome segments instead of each SNP individually (Kirin et al., 2010). The IBD status of a chromosome segment, often referred to as chromosome segment homozygosity, is defined as the probability that 2 chromosome segments of the same size and location drawn at random from the population are from a common ancestor, without intervening recombination, and can be calculated as outlined by Hayes et al. (2003). Alternatively, the IBS status of a segment (i.e., $\mathrm{ROH}$ status) can be used and, provided the number of markers in the haplotype is large, the probability of IBS and IBD will be similar. Methods to construct ROH-based relationship metrics have been developed by deriving probabilities of segment IBD (MacLeod et al., 2009) or using the observed markers to calculate the ROH status of a given haplotype length (Pryce et al., 2012a).

In livestock, several correlations between pedigree and genomic-based relationship and inbreeding metrics have been estimated. Across 3 dairy breeds in the United States, VanRaden et al. (2011b) estimated a correlation ranging from 0.50 to 0.56 between pedigreeand genomic-based inbreeding coefficients. As shown by Pryce et al. (2012a), the correlation between $\mathbf{A}$ and $\mathbf{G}$ is dependent on the depth of the pedigree. When the number of generations of recorded ancestry was 2 , 4,6 , and 8 , the correlation between $\mathbf{G}$ and pedigree was $0.67,0.73,0.84$, and 0.87 , respectively. Hayes and Goddard (2008) obtained a correlation of 0.69 between A- and G-based relationship coefficients in a population of Australian Angus bulls. An $\mathrm{ROH}$ coancestry matrix with a length of 50 SNP (approximately 3.35 $\mathrm{Mb}$ ) was constructed in Pryce et al. (2012a) and the correlation was 0.69 and 0.64 with $\mathbf{G}$ and $\mathbf{A}$, respectively. Furthermore, using simulation, Keller et al. (2011) found that across various effective population sizes inbreeding based on $\mathrm{ROH}$ correlates most highly with the pedigree-based inbreeding compared with SNP-by-SNP-based inbreeding metrics. This higher correlation reflects the fact that $\mathrm{ROH}$-based inbreeding based on comparatively longer $\mathrm{ROH}$ tends to capture more recent inbreeding than SNP-by-SNP-based genomic estimates.

As emphasized throughout this review, the main limitation of pedigree information is that it is an expected value and may contain parentage errors. Therefore, more precise estimates of the actual relationship can be obtained with molecular information. The majority of methods that have investigated the use of a $\mathbf{G}$ have shown its ability to accurately predict the phenotype or genetic worth of animal (Hayes et al., 2009). In the context of managing a population at the genomic level, research on the consequence of different weighting methods during the construction of $\mathbf{G}$ on the long-term genetic diversity within regions of low and high genetic diversity has yet to be fully understood. Methods outlined previously that reweight relationship matrices can also be augmented to construct $\mathbf{G}$ based on the SNP diversity of a region to minimize the probability that regions of low diversity are lost by drift.

\section{MANAGING GENETIC DIVERSITY}

The maintenance of genetic diversity within a population is achieved by maximizing the effective population size $(\mathrm{Ne})$ of a population, or equivalently, by minimizing the increase in inbreeding across generations (de Cara et al., 2013a). The $\mathrm{Ne}$ of a population 
was developed by Wright (1931) and is defined as the size of an idealized population undergoing the same rate of genetic drift as the population under study (Falconer and Mackay, 1996). A large number of methods to estimate Ne from either demographic, pedigree, or molecular data have been proposed (Caballero, 1994; Luikart et al., 2010; Leroy et al., 2013). In the ideal scenario, population genetics theory recommends keeping equal numbers of males and females and maintaining a constant population size over time. In this situation, equalizing contributions (i.e., forcing every individual to contribute one male and one female offspring) would maximize $\mathrm{Ne}$, being nearly twice that of an idealized population (Falconer and Mackay, 1996). Given that for most livestock maximizing the genetic response in the current generation is the primary goal, along with logistics and managing constraints, it is often impossible to maintain a 1:1 sex ratio. Animal populations are therefore maintained with far fewer males than females, which greatly affects the Ne of a population.

\section{Effective Population Size}

Given the importance of managing the genetic diversity, an important question is what is an acceptable rate of inbreeding (or smallest $\mathrm{Ne}$ ) to maintain adequate genetic diversity (Meuwissen, 2009). The effective population size across many livestock breeds is below 100 (Leroy et al., 2013). The skewed distribution of genetic contributions resulting from intense directional artificial selection of a few animals is one of the reasons why Ne values below 100 are observed for many modern breeds. For example, the Holstein dairy cattle breed has a census size of millions of individuals, although the $\mathrm{Ne}$ of the whole population is estimated to be 100 (Sørensen et al., 2005; Stachowicz et al., 2011). As a result, the Holstein breed is accumulating inbreeding at the same rate as an idealized population of only 100 individuals. Quantitative genetic theory predicts that $\mathrm{Ne}$ is positively associated with the level of additive genetic variation, and therefore represents the capacity of a population to respond to natural selection and the ability to evolve and adapt to the changes in its environment (Falconer and Mackay, 1996). However, a small Ne in domesticated animal populations helps produce phenotypic uniformity within populations (Janhunen et al., 2013); therefore, a tradeoff exists in dairy populations to maintain uniformity while also minimizing the unfavorable effects of inbreeding. Despite the low $\mathrm{Ne}$, large and ongoing genetic gains for production traits are typically achieved in commercial livestock, and there are no apparent signs of reaching selection plateaus (Hill and Kirkpatrick, 2010). Although, many domestic species have long generation intervals, intense selection within domestic breeds has (from an evolutionary point of view) not been practiced for long. The breed concept is not more than approximately $200 \mathrm{yr}$ old, and reproductive technologies enabling intense selection have only been in common use since the 1960s (Taberlet et al., 2008). Across both domestic and wild populations, the minimal Ne to avoid inbreeding depression in the short term is at least 50 , whereas a Ne of at least 500 is sufficient to retain long-term evolutionary potential (Franklin, 1980; Soule, 1980; Franklin and Frankham, 1998; Holt et al., 2005; Meuwissen, 2009). In a long-term (120 generations) selection experiment in mice, several lines were kept at an average Ne of 60 and no apparent inbreeding problems existed (Holt et al., 2005). A simulation study by Meuwissen and Woolliams (1994) has further highlighted that if fitness declines as a correlated negative response to artificial selection on a quantitative trait, then a large increase in the critical Ne is needed.

The majority of metrics to estimate Ne assume the value as constant across the genome. However, the $\mathrm{Ne}$ estimate varies across the genome, so that some regions have increased loss of diversity compared with others (Gossmann et al., 2011; Jiménez-Mena et al., 2016a). The Ne is expected to vary across the genome as a consequence of genetic hitchhiking due to selection (Smith and Haigh, 1974) and negative selection acting on deleterious mutations (i.e., background selection; Charlesworth et al., 1993). The action of selection, particularly in regions of the genome with low rates of recombination, is expected to reduce the $\mathrm{Ne}$, leading to lower levels of genetic diversity and reduced effectiveness of selection. Hence the variation in the rate of recombination and the density of selected sites is expected to generate variation in Ne (Gossmann et al., 2011). The heterogeneity in livestock is scarce, although Jiménez-Mena et al. (2016b) found the Ne to vary considerably across the genome $(\mathrm{Ne}=40-250)$ in a Danish Holstein population. Thus, the accumulation of inbreeding is heterogeneous across the genome, such that certain regions are being inbred at a faster rate than other regions of the genome.

\section{Method to Manage a Population}

Current strategies used to control the accumulation of inbreeding in the context of dairy cattle breeding range from naïve to complex strategies. A simple method that has been traditionally used to control inbreeding is to avoid matings of genetically related animals based on tracing the pedigree back for a given number of generations (Weigel and Lin, 2000). More complex methods 
can be classified into managing inbreeding at the population levels by restricting the rate of inbreeding in the whole population, or at the animal level by restricting the coancestry between mating pairs (Fernández et al., 2000). Restricting the rate of inbreeding in the whole population can be done indirectly by reducing the weight given to family information at the selection step (Grundy et al., 1994). Alternatively, a direct method, referred to as optimal contribution selection, maximizes the selection objective while constraining progeny inbreeding to a predefined level (Wray and Goddard, 1994; Meuwissen, 1997; Grundy et al., 1998).

Methods that manage a population at the animal level include compensatory mating (i.e., mating between males with high average coancestry and females with low average coancestry; Caballero et al., 1996), factorial mating and mating individuals in a manner that yields the lower average pairwise coancestry between mating pairs (Toro et al., 1988), or between the mean coancestry of an individual and the rest of the population (Ballou and Lacy, 1995). Alternatively, the expected inbreeding of future progeny, which is defined as the mean relationship of an individual with individuals in the whole population, can be computed (VanRaden and Smith, 1999). The resulting estimates can then be used to penalize or improve the breeding values of potential selection candidates that are either highly or lowly related to individuals in the whole population. Avoiding high inbreeding levels in the progeny through control of matings is advantageous to minimize the number of lethal recessive alleles and genome homozygosity in the progeny. The process of selecting and allocating male and female individuals into mating pairs is referred to as mate selection (Allaire, 1980). The criteria to choose mating pairs can be a function of a large number of variables, including the expected genetic merit and inbreeding of the progeny, coancestry among parents used in the mating set, number of times sire was given a mating pair, and probability of inheriting a homozygous lethal recessive (Kinghorn, 2011). Furthermore, in the context of a large number of herds or predefined groups of animals, mate selection can be used to keep certain group constraints set or increase connectivity or migration of breeding stock across herds (Kinghorn, 2011). A large number of mate selection algorithms have been developed with varying degrees of complexity and include linear programming (Jansen and Wilton, 1985), sequential selection of least-related mates (Pryce et al., 2012a; Cole, 2015), simulated annealing (Kirkpatrick et al., 1983), and evolutionary algorithms (Kinghorn and Shepherd, 1999; Carvalheiro et al., 2010; Kinghorn, 2011). Previous work in dairy cattle has highlighted the benefits of more complex mate allocation methods, such as linear programming, which had a $\$ 17$ advantage per mating in Holstein estimated lifetime profit over using a simple limit to avoid inbreeding and a $\$ 37$ advantage per mating over random mating (Weigel and Lin, 2000).

The genetic relationships used to constrain the average parental relationships within a generation can come from a variety of sources. Multiple studies based on marker information have shown that managing a population using molecular coancestry of the parents can maintain more diversity than using pedigree-based coancestries (de Cara et al., 2011; Engelsma et al., 2011; Sonesson et al., 2012; de Cara et al., 2013a; Sun et al., 2013; Bosse et al., 2015; Rodríguez-Ramilo et al., 2015). For example, Sun et al. (2013) found that the expected genomic inbreeding in US Holstein progeny was reduced by $1.41 \%$ when mating was conducted with the linear programming algorithm utilizing genomic rather than pedigree information. A slightly smaller reduction $(0.9 \%)$ in expected genomic inbreeding in the progeny when mating was conducted with the sequential selection of least-related mates algorithm utilizing genomic rather than pedigree information was found by Pryce et al. (2012) utilizing an Australian Holstein population. In the context of optimal contribution selection, the information source used to predict breeding values and to constrain relationships needs to be identical, as outlined by Sonesson et al. (2012). If the information sources are identical, either pedigree- or genomic-based, then the resulting rates of genomic inbreeding correspond to the desired values or the rates are reasonably uniform across the genome. Lastly, previous research has also shown that kinships are not minimized if they are based on another source of information (pedigree or genomic), such as constraining based on pedigree while trying to minimize the molecular inbreeding value (Engelsma et al., 2011).

One caveat of maintaining global genetic diversity by optimizing contributions is that mutations that are deleterious may remain segregating in the population, thereby reducing the mean fitness of the population. A strategy to avoid this problem is to combine optimal contribution selection with inbred matings to expose and purge deleterious recessive mutations (de Cara et al., 2013b). Alternatively, the use of a relationship matrix based on $\mathrm{ROH}$ has been previously shown to be a compromise between maintaining diversity and fitness, especially when the population has some inbreeding load (de Cara et al., 2013a; Bosse et al., 2015). In humans, it has been shown that positive selection has had a significant effect on deleterious polymorphisms, such that fewer neutral but a similar number of deleterious SNP were discovered with regions having undergone 
selection compared with other genomic regions (Chun and Fay, 2011). This implies that, for dairy cattle populations that have been intensely selected for multiple generations, positive selection on traits of interest could potentially increase, via hitchhiking, the frequency of linked deleterious alleles. Therefore, a reduction in the footprint of selection may be advantageous, and this can be achieved by increasing the frequency of a broad spectrum of QTL alleles slowly instead of heavily selecting a small set of QTL with large effects, with the danger of a large selection footprint (Pedersen et al., 2010; Sonesson et al., 2012). This can be achieved by generating breeding values based on marker effects that have been weighted by the inverse of their allele frequencies, such that favorable alleles that are at a low frequency receive a higher weight to avoid losing such alleles (Goddard, 2009; Jannink, 2010; Sun and VanRaden, 2014; Liu et al., 2015).

The method used to estimate breeding values for selection purposes also has an effect on the uniformity of inbreeding across the genome and the change in inbreeding levels across the long-term time horizon. It was shown by Sonesson et al. (2012) that methods assuming a few large QTL, such as BayesB, result in an IBD profile with less uniformity than methods assuming a polygenic architecture. Furthermore, it has been shown by Liu et al. (2014) and Pedersen et al. (2010) that the hitchhiking effect at genomic locations harboring a QTL under genomic selection can be large compared with selection based on pedigree information. In the context of long-term genetic gain, it was shown by Liu et al. (2015) that Bayesian Lasso achieved greater genetic gains and reduced inbreeding rates compared with Bayesian Ridge Regression. Although, it should be noted that inbreeding at QTL positions is desirable in breeding schemes because this increases the frequency of the positive alleles toward fixation. However, narrowing the genomic IBD peak at QTL positions is also desired, so that the remaining genome is not greatly affected by selection at individual QTL. This results in the footprint of selection being as minimal as possible, and minimizes the loss of favorable mutations due to drift surrounding the selected QTL (Sonesson et al., 2012).

The use of molecular data allows for diversity at specific regions to be evaluated and monitored instead of utilizing genome-wide diversity metrics (Engelsma et al., 2010). The use of genome-wide metrics disregards the fact that certain regions of the genome are becoming inbred at a faster rate than others. For example, for regions that harbor loci involved in general resistance to disease (i.e., the major histocompatibility complex), a high level of genetic diversity is desirable to ensure that the population can deal with potential new disease challenges. This is also the case in the context of heterogeneous inbreeding, which has been shown to occur in dairy cattle, as outlined in the Inbreeding section. Previous research has identified lethal mutations or regions that, when contained in a long stretch of homozygosity, result in reduced performance (VanRaden et al., 2011a; Pryce et al., 2014; Howard et al., 2015a). Thus, animal-breeding programs could be more efficient if approaches to maintaining genetic diversity are focused on some regions of the genome rather than on the whole genome. However, such approaches require that constraints on coancestry be imposed on the rest of the genome; otherwise, rates of coancestry, inbreeding, and loss of variability could become high in regions that are positioned away from the region targeted for minimization (Gómez-Romano et al., 2016). In the context of optimal contribution selection, methods have been developed to constrain inbreeding at specific regions and across the whole genome (Roughsedge et al., 2008; Gómez-Romano et al., 2016), although the regions which are constrained need to be known a priori.

Genetic evaluations often ignore nonadditive genetic effects, such as dominance and epistasis, and their expression in the forms of heterosis and inbreeding depression, although their potential importance in mating programs has been extensively discussed. In many cases, this is justified by the relatively minor effect they make on the outcome of selection decisions. However, as breeding goals become more complex in recognition of the need to maintain fitness as well as improve productivity, there may be a need to review this position. Particularly because nonadditive effects are considered to have a greater effects on traits associated with fitness, which are more likely to exhibit dominance or epistasis than production-related traits (Wall et al., 2005). The use of dominance effects in mating designs has been investigated utilizing pedigree information (DeStefano and Hoeschele, 1992; VanRaden et al., 1992; Misztal et al., 1998). The use of dominance effects in mating designs is important to identify mating pairs with good combining abilities by recovering inbreeding depression and utilizing possible overdominance (Wellmann and Bennewitz, 2012). Results from simulation provide evidence that the inclusion of dominance in mating designs does improve the expected genetic response in the first generation, although its improvement is eroded after a few generations. Thus, a continued collection of phenotypic data and reevaluation will be required (Toro and Varona, 2010). A study by Sun et al. (2013) found that the inclusion of dominance effects can increase the expected progeny milk genetic value by 86 $\mathrm{kg}$ for US Holsteins and $52 \mathrm{~kg}$ for US Jerseys compared with mating programs that only included additive genetic effects. 
EMERGENCE OF NEW TECHNOLOGIES AND THEIR EFFECT ON MANAGING POPULATIONS

The use of genomic information will greatly improve the understanding of the genetic architecture of inbreeding depression in terms of the identification of lethal haplotypes and regions of the genome that are sensitive to inbreeding, although the management of the associated haplotypes is likely to become increasingly complex. For example, it has been estimated that each human genome contains approximately 100 loss-of-function mutations and about 20 genes that are completely inactivated (MacArthur et al., 2012). As outlined by Van Eenennaam and Kinghorn (2014), as the number of lethal loci increases, selection or mating strategies will need to optimize the balance between compromises in genetic gain and reducing the effect of inbreeding depression. A large number of either lethal or unfavorable haplotypes across multiple economically important traits will eventually be identified. Thus, methods need to be developed that effectively take into account the probability of occurring within an individual or progeny, along with their individual importance to the overall breeding objective.

Genetic diversity within or across countries (Kim et al., 2013; Howard et al., 2015b) and recombination frequency for particular regions of the genome (Ma et al., 2015), along with a list of positions of putative QTL across a variety of traits (Hu et al., 2013), have all been investigated, such that the structure of the genome for a population can already to some extent be exploited in breeding programs. Although the interplay between these factors has yet to be fully understood, the relationship between the effect of selection occurring at genomic regions and the sensitivity of a region experiencing a large reduction in the genetic diversity surrounding the selected regions needs to be better understood. The length of the region affected by selection is due to multiple factors, including the model used to generate breeding values, recombination rate, and current genetic diversity. Recently, a high-resolution recombination map was generated by Ma et al. (2015), which highlighted the variation in recombination across the genome, recombination hotspots, and the recombination rate across time. Therefore, methods need to be developed to exploit knowledge on recombination cold spots and a priori knowledge of low-diversity regions to limit regions undergoing a large decrease in the $\mathrm{Ne}$, resulting in increased $\mathrm{ROH}$ frequency and greater potential to harbor deleterious mutations. Likewise, during the process of driving favorable alleles to fixation, deleterious alleles may also be hitchhiked along with favorable mutations. In the optimal scenario, a breeding program drives favorable alleles to fixation while limiting the effect of regions surrounding the favorable allele; the incorporation of genomic features that may influence the length of the hitchhiking would greatly improve the effectiveness. Therefore, research on optimal methods to generate breeding values that minimize the hitchhiking effect while maximizing the prediction accuracy is needed.

The use of semen and embryo biotechnologies with genomic selection have great potential to further increase the rate of genetic gain, as outlined by Ponsart et al. (2013); however, in general most of these methods result in increased levels of inbreeding due to more intense selection on a smaller set of candidates. Therefore, programs that use these technologies will need even more sophisticated mating design support tools to balance the trade-off between genetic gain in the current generation versus long-term genetic gain and the frequency of unfavorable regions. Furthermore, the study by Ma et al. (2015) observed that the male recombination rate has decreased over time, which has implications in terms of the ability to generate new favorable combinations of haplotypes within given regions. The ability to generate combinations of haplotypes that are extreme versus genetic uniformity within a bull crop and its relationship with the recombination frequency across the genome within elite herds remains to be investigated.

In general, across the majority of species, the primary use of genomic information is as a tool to more effectively estimate the genetic merit of a young animal for ranking and subsequent selection. Although limited, other uses of genomic information are starting to emerge, such as determining the carrier status of an animal for currently known lethal mutations (Cole, 2015) or calculating genomic inbreeding estimates (Sun et al., 2013). The supplemental uses of genomic information are still, for the most part, geared toward characterizing the diversity of an individual and not necessarily the animal's genome conditional on the herd it is destined to serve as a breeder in, although this would require whole-herd genotyping. Although a limited number of dairy herds are conducting whole-herd genotyping, this is a great opportunity to maximize the information garnered from genomic information. In addition to estimating the genetic merit of an individual, the task of genotyping also needs to consider an animal's (i.e., sire or replacement heifer selection candidate) effect on the genomic profile of a herd in terms of genetic merit, genetic diversity, haplotype diversity, and unfavorable haplotypes across the genome. The outcome of a more precise genomic profile of a herd could result in a breeder more effectively identifying problem areas of the genome in terms of diversity, genetic merit, or unfavorable haplotype frequencies instead of just relying 
on genome-wide metrics. Furthermore, one of the major pitfalls with the identification of unfavorable regions of the genome is that they are expected to be carried at a low frequency at the population level. A portion of herds are likely carrying the unfavorable region(s) at a higher frequency due to routinely using bloodlines carrying such regions. The use of genomic information to identify these detrimental regions, along with mating plans to minimize their frequency at the herd level, provides a great opportunity to minimize the spread of pernicious regions to the whole population. One major roadblock currently is the lack of efficient and optimal algorithms to accurately identify inbreeding footprints. Likewise, delivering genomic profiles to a herd based on a given mating design requires genomic information to be easily passed across stakeholders (i.e., breeding organization, AI company, commercial farm), a process that is often impaired by the logistic of data flow. An opportunity exists to develop visualization software to provide the breeder with feedback on regions of the genome that are suboptimal from a genetic merit perspective, or that are sensitive to inbreeding within a herd. In these cases, mating steps can be used to improve those regions along with the genome-wide genetic value. A related topic was mentioned by Cole and Null (2013) and Cole and VanRaden (2010) in terms of visualizing the results of genomic evaluations.

Several methods have been developed to optimally manage the inbreeding levels within a population based on either pedigree or more recently genomic information. One caveat across the majority of all these methods is their lack of flexibility. A large number of factors in addition to inbreeding levels come into play when choosing AI sires and replacement animals within a herd, including breeder preference and nonlinear traits such as body conformation and economical constraints. As a result, it is difficult to develop sire selection and or mating tools that encompass all of the possible factors that are involved in sire and mate selection. Furthermore, the ability of small cattle breeds to use novel genomic tools to manage genetic diversity is limited due to a lack of infrastructure by their associations, which is a concern if we are not to lose their breed strength in the future. Thus, even though genomic information does provide a great opportunity to more effectively manage the risks associated with inbreeding, the optimal implementation of the previously described methods at the farm is as or even more important. As pointed out by Cole (2015), algorithms that are easy to implement and provide flexibility are more likely to be used by the industry, even though they may not have theoretically optimal properties, and it is better to have an imperfect genomic management tool used than no tool at all. The implementation genomic tools to manage a population in integrated industries (i.e., swine and chicken) is much more straightforward due to populations being managed within nucleus populations. Dairy cattle populations are, for the most part, a dispersed industry, with several elite nucleus herds supplying breeding stock to the global industry. Furthermore, the intense marketing of elite bulls by AI companies gives rise to short-term genetic gains being of primary importance. Therefore, tools to aid AI companies in marketing bull groups that have low levels of relationship at the genomic level may be a practical approach in mating designs for large commercial herds, where mating plans at the individual animal level may be too time-consuming.

\section{CONCLUSIONS AND IMPLICATIONS}

The use of genomic information to manage a population provides a great opportunity for dairy breeders to accelerate genetic improvement and minimize the effects associated with elevated inbreeding levels. As illustrated throughout the manuscript, the incorporation of region-specific homozygosity metrics holds great promise to more effectively manage inbreeding. As a result, breeders are able to identify problem areas (i.e., diversity, genetic merit, or unfavorable haplotype) across the genome within their herd, and steps at the mating level can be used to improve the region(s). Before, these sophisticated management techniques are used, a large amount of research needs to be conducted on methods of identifying regions of the genome affected by inbreeding and its optimal use at the herd level. Genomic information also needs to be easily passed across stakeholders to precisely determine how the use of a bull within a herd affects the associated progeny at the genomic level. The use of visualization software holds great promise as a tool for the breeder to more effectively illustrate how a set of candidate sires and dams will affect the genome of the progeny in terms of the genetic value and genetic load carried by the progeny population.

\section{ACKNOWLEDGMENTS}

C. Baes gratefully acknowledges financial support through NSERC.

\section{REFERENCES}

Agerholm, J. S., C. Bendixen, O. Andersen, and J. Arnbjerg. 2001. Complex vertebral malformation in holstein calves. J. Vet. Diagn. Invest. 13:283-289.

Aguilar, I., I. Misztal, A. Legarra, and S. Tsuruta. 2011. Efficient computation of the genomic relationship matrix and other matrices 
used in single-step evaluation. J. Anim. Breed. Genet. 128:422428. https://doi.org/10.1111/j.1439-0388.2010.00912.x.

Aliloo, H., J. E. Pryce, O. González-Recio, B. G. Cocks, M. E. Goddard, and B. J. Hayes. 2017. Including nonadditive genetic effects in mating programs to maximize dairy farm profitability. J. Dairy Sci. 100:1203-1222. https://doi.org/10.3168/jds.2016-11261.

Aliloo, H., J. E. Pryce, O. González-Recio, B. G. Cocks, and B. J. Hayes. 2016. Accounting for dominance to improve genomic evaluations of dairy cows for fertility and milk production traits. Genet. Sel. Evol. 48:8.

Allaire, F. R. 1980. Mate selection by selection index theory. Theor. Appl. Genet. 57:267-272.

Amin, N., C. M. van Duijn, and Y. S. Aulchenko. 2007. A genomic background based method for association analysis in related individuals. PLoS One 2:e1274.

Ballou, J. D., and R. C. Lacy. 1995. Identifying genetically important individuals for management of genetic diversity in pedigreed populations. Pages 76-111 in Population Management for Survival \& Recovery. Columbia Press, New York, NY.

Bjelland, D. W., K. A. Weigel, N. Vukasinovic, and J. D. Nkrumah. 2013. Evaluation of inbreeding depression in Holstein cattle using whole-genome SNP markers and alternative measures of genomic inbreeding. J. Dairy Sci. 96:4697-4706.

Boakes, E. H., J. Wang, and W. Amos. 2007. An investigation of inbreeding depression and purging in captive pedigreed populations. Heredity (Edinb.) 98:172-182.

Bosse, M., H.-J. Megens, O. Madsen, R. P. M. A. Crooijmans, O. A. Ryder, F. Austerlitz, M. A. M. Groenen, and M. A. R. de Cara. 2015. Using genome-wide measures of coancestry to maintain diversity and fitness in endangered and domestic pig populations. Genome Res. 25:970-981. https://doi.org/10.1101/gr.187039.114.

Caballero, A. 1994. Developments in the prediction of effective population size. Heredity (Edinb.) 73:657-679.

Caballero, A., E. Santiago, and M. Toro. 1996. Systems of mating to reduce inbreeding in selected populations. Anim. Sci. 62:431-442.

Carvalheiro, R., B. P. Kinghorn, and S. a. Queiroz. 2010. Mate Selection Accounting for Connectedness. In Proceedings of the 9th World Congress on Genetics Applied to Livestock Production, Leipzig, Germany, August 1-6.

Charlesworth, B., M. T. Morgan, and D. Charlesworth. 1993. The effect of deleterious mutations on neutral molecular variation. Genetics 134:1289-1303.

Charlesworth, D., and B. Charlesworth. 1987. Inbreeding depression and its evolutionary consequences. Annu. Rev. Ecol. Syst. 18:237268.

Chun, S., and J. C. Fay. 2011. Evidence for hitchhiking of deleterious mutations within the human genome. PLoS Genet. 7:e1002240. https://doi.org/10.1371/journal.pgen.1002240.

Cockerham, C. C. 1954. An extension of the concept of partitioning hereditary variance for analysis of covariances among relatives when epistasis is present. Genetics 39:859-882.

Cole, J. B. 2015. A simple strategy for managing many recessive disorders in a dairy cattle breeding program. Genet. Sel. Evol. 47:94.

Cole, J. B., and D. J. Null. 2013. Visualization of the transmission of direct genomic values for paternal and maternal chromosomes for 15 traits in US Brown Swiss, Holstein, and Jersey cattle. J. Dairy Sci. 96:2713-2726. https://doi.org/10.3168/jds.2012-6008.

Cole, J. B., and P. M. VanRaden. 2010. Visualization of results from genomic evaluations. J. Dairy Sci. 93:2727-2740. https://doi. org/10.3168/jds.2009-2763.

Colleau, J.-J. 2002. An indirect approach to the extensive calculation of relationship coefficients. Genet. Sel. Evol. 34:409-421.

Crow, J. F., and M. Kimura. 1970. An Introduction to Population Genetics Theory. Blackburn Press, Caldwell, NJ.

de Cara, M. Á. R., J. Fernandez, M. Á. Toro, and B. Villanueva. 2011. Using genome-wide information to minimize the loss of diversity in conservation programmes. J. Anim. Breed. Genet. 128:456-464.

de Cara, M. Á. R., B. Villanueva, M. Á. Toro, and J. Fernández. 2013a. Using genomic tools to maintain diversity and fitness in conservation programmes. Mol. Ecol. 22:6091-6099. de Cara, M. Á. R., B. Villanueva, M. Á. Toro, and J. Fernández. 2013b. Purging deleterious mutations in conservation programmes: Combining optimal contributions with inbred matings. Heredity (Edinb.) 110:530-537.

de Los Campos, G., A. I. Vazquez, R. Fernando, Y. C. Klimentidis, and D. Sorensen. 2013. Prediction of complex human traits using the genomic best linear unbiased predictor. PLoS Genet. 9:e1003608.

DeStefano, A. L., and I. Hoeschele. 1992. Utilization of dominance variance through mate allocation strategies. J. Dairy Sci. 75:16801690.

Engelsma, K. A., M. P. L. Calus, P. Bijma, and J. J. Windig. 2010. Estimating genetic diversity across the neutral genome with the use of dense marker maps. Genet. Sel. Evol. 42:12.

Engelsma, K. A., R. F. Veerkamp, M. P. L. Calus, and J. J. Windig. 2011. Consequences for diversity when prioritizing animals for conservation with pedigree or genomic information. J. Anim. Breed. Genet. 128:473-481.

Ertl, J., A. Legarra, Z. G. Vitezica, L. Varona, C. Edel, R. Emmerling, and K.-U. Götz. 2014. Genomic analysis of dominance effects on milk production and conformation traits in Fleckvieh cattle. Genet. Sel. Evol. 46:40.

Falconer, D. S., and T. F. C. Mackay. 1996. Introduction to Quantitative Genetics. 4th ed. Longman Scientific and Technical, New York, NY.

Fernández, B., E. Santiago, M. A. Toro, and A. Caballero. 2000. Effect of linkage on the control of inbreeding in selection programmes. Genet. Sel. Evol. 32:249-264.

Fisher, R. A. 1954. A fuller theory of "junctions" in inbreeding. Heredity 8:187-197. https://doi.org/10.1038/hdy.1954.17.

Franklin, I. R. 1977. The distribution of the proportion of the genome which is homozygous by descent in inbred individuals. Theor. Popul. Biol. 11:60-80.

Franklin, I. R. 1980. Evolutionary change in small populations. Pages 135-149 in Conservation Biology: An Evolutionary-Ecological Perspective. Sinauer, Sunderland, MA.

Franklin, I. R., and R. Frankham. 1998. How large must populations be to retain evolutionary potential? Anim. Conserv. 1:69-70.

Fu, Y.-B., G. Namkoong, and J. E. Carlson. 1998. Comparison of breeding strategies for purging inbreeding depression via simulation. Conserv. Biol. 12:856-864.

García-Ruiz, A., J. B. Cole, P. M. VanRaden, G. R. Wiggans, F. J. Ruiz-López, and C. P. Van Tassell. 2016. Changes in genetic selection differentials and generation intervals in US Holstein dairy cattle as a result of genomic selection. Proc. Natl. Acad. Sci. USA 113:E3995-E4004. https://doi.org/10.1073/pnas.1519061113.

Goddard, M. 2009. Genomic selection: prediction of accuracy and maximisation of long term response. Genetica 136:245-257.

Gomez-Raya, L., C. Rodríguez, C. Barragán, and L. Silió. 2015. Genomic inbreeding coefficients based on the distribution of the length of runs of homozygosity in a closed line of Iberian pigs. Genet. Sel. Evol. 47:81.

Gómez-Romano, F., B. Villanueva, J. Fernández, J. A. Woolliams, and R. Pong-Wong. 2016. The use of genomic coancestry matrices in the optimisation of contributions to maintain genetic diversity at specific regions of the genome. Genet. Sel. Evol. 48:2.

Gossmann, T. I., M. Woolfit, and A. Eyre-Walker. 2011. Quantifying the variation in the effective population size within a genome. Genetics 189:1389-1402.

Grundy, B., A. Caballero, E. Santiago, and W. G. Hill. 1994. A note on using biased parameter values and non-random mating to reduce rates of inbreeding in selection programmes. Anim. Prod. 59:465-468.

Grundy, B., B. Villanueva, and J. A. Woolliams. 1998. Dynamic selection procedures for constrained inbreeding and their consequences for pedigree development. Genet. Res. 72:159-168.

Gulisija, D., and J. F. Crow. 2007. Inferring purging from pedigree data. Evolution 61:1043-1051. 
Gulisija, D., D. Gianola, and K. A. Weigel. 2007. Nonparametric analysis of the impact of inbreeding on production in Jersey cows. J. Dairy Sci. 90:493-500.

Guo, S. W. 1996. Variation in genetic identity among relatives. Hum. Hered. 46:61-70.

Häggman, J., and P. Uimari. 2016. Novel harmful recessive haplotypes for reproductive traits in pigs. J. Anim. Breed. Genet. 134:129135. https://doi.org/10.1111/jbg.12240.

Hayes, B. J., P. J. Bowman, A. J. Chamberlain, and M. E. Goddard. 2009. Invited review: Genomic selection in dairy cattle: Progress and challenges. J. Dairy Sci. 92:433-443.

Hayes, B. J., and M. E. Goddard. 2008. Technical note: Prediction of breeding values using marker-derived relationship matrices. J. Anim. Sci. 86:2089-2092.

Hayes, B. J., P. M. Visscher, H. C. McPartlan, and M. E. Goddard. 2003. Novel multilocus measure of linkage disequilibrium to estimate past effective population size. Genome Res. 13:635-643.

Hedrick, P. W. 1994. Purging inbreeding depression and the probability of extinction: Full-sib mating. Heredity (Edinb.) 73:363-372.

Heidaritabar, M., A. Wolc, J. Arango, J. Zeng, P. Settar, J. E. Fulton, N. P. O'Sullivan, J. W. M. Bastiaansen, R. L. Fernando, D. J. Garrick, and J. C. M. Dekkers. 2016. Impact of fitting dominance and additive effects on accuracy of genomic prediction of breeding values in layers. J. Anim. Breed. Genet. 133:334-346.

Hill, W. G. 1993. Variation in genetic identity within kinships. Heredity $71: 652-653$.

Hill, W. G., and M. Kirkpatrick. 2010. What animal breeding has taught us about evolution. Annu. Rev. Ecol. Evol. Syst. 41:1-19.

Hill, W. G., and B. S. Weir. 2011. Variation in actual relationship as a consequence of Mendelian sampling and linkage. Genet. Res. (Camb.) 93:47-64.

Holt, M., T. Meuwissen, and O. Vangen. 2005. Long-term responses, changes in genetic variances and inbreeding depression from 122 generations of selection on increased litter size in mice. J. Anim. Breed. Genet. 122:199-209.

Howard, J. T., M. Haile-Mariam, J. E. Pryce, and C. Maltecca. 2015a. Investigation of regions impacting inbreeding depression and their association with the additive genetic effect for United States and Australia Jersey dairy cattle. BMC Genomics 16:813.

Howard, J. T., C. Maltecca, M. Haile-Mariam, B. J. Hayes, and J. E. Pryce. 2015b. Characterizing homozygosity across United States, New Zealand and Australian Jersey cow and bull populations. BMC Genomics 16:187.

Hu, Z.-L., C. A. Park, X.-L. Wu, and J. M. Reecy. 2013. Animal QTLdb: An improved database tool for livestock animal QTL/association data dissemination in the post-genome era. Nucleic Acids Res. 41:D871-D879.

Jain, S. K., and R. W. Allard. 1966. The effects of linkage, epistasis, and inbreeding on population changes under selection. Genetics 53:633-659.

Janhunen, M., A. Kause, E. A. Mantysaari, H. Vehvilainen, A. K. Praebel, O. Jarvisalo, T. Paananen, and H. Koskinen. 2013. A novel breeding design to produce genetically protected homogenous fish populations for on-growing. Aquacult. Res. 44:1847-1859.

Jannink, J.-L. 2010. Dynamics of long-term genomic selection. Genet. Sel. Evol. 42:35

Jansen, G. B., and J. W. Wilton. 1985. Selecting mating pairs with linear programming techniques. J. Dairy Sci. 68:1302-1305.

Jiménez-Mena, B., F. Hospital, and T. Bataillon. 2016a. Heterogeneity in effective population size and its implications in conservation genetics and animal breeding. Conserv. Genet. Resour. 8:35-41.

Jiménez-Mena, B., P. Tataru, R. F. Brøndum, G. Sahana, B. Guldbrandtsen, and T. Bataillon. 2016b. One size fits all? Direct evidence for the heterogeneity of genetic drift throughout the genome. Biol. Lett. 12: 20160426. https://doi.org/10.1098/rsbl.2016.0426.

Keller, M. C., M. A. Simonson, S. Ripke, B. M. Neale, P. V. Gejman, D. P. Howrigan, S. H. Lee, T. Lencz, D. F. Levinson, P. F. Sullivan, and Schizophrenia Psychiatric Genome-Wide Association Study Consortium. 2012. Runs of homozygosity implicate autozygosity as a schizophrenia risk factor. PLoS Genet. 8:e1002656. https://doi.org/10.1371/journal.pgen.1002656.
Keller, M. C., P. M. Visscher, and M. E. Goddard. 2011. Quantification of inbreeding due to distant ancestors and its detection using dense single nucleotide polymorphism data. Genetics 189:237-249.

Kim, E.-S., J. B. Cole, H. Huson, G. R. Wiggans, C. P. Van Tassell, B. A. Crooker, G. Liu, Y. Da, and T. S. Sonstegard. 2013. Effect of artificial selection on runs of homozygosity in u.s. Holstein cattle. PLoS One 8:e80813.

Kinghorn, B. P. 2011. An algorithm for efficient constrained mate selection. Genet. Sel. Evol. 43:4.

Kinghorn, B. P., and R. K. Shepherd. 1999. Mate selection for the tactical implementation of breeding programs. Proc. Assoc. Adv. Anim. Breed. Genet. 13:130-133.

Kirin, M., R. McQuillan, C. S. Franklin, H. Campbell, P. M. McKeigue, and J. F. Wilson. 2010. Genomic runs of homozygosity record population history and consanguinity. PLoS One 5:e13996.

Kirkpatrick, S., C. D. Gelatt, and M. P. Vecchi. 1983. Optimization by simulated annealing. Science 220:671-680.

Kristensen, T. N., and A. C. Sorensen. 2005. Inbreeding-Lessons from animal breeding, evolutionary biology and conservation genetics. Anim. Sci. 80:121-133.

Lacy, R. C., G. Alaks, and A. Walsh. 1996. Hierarchical analysis of inbreeding depression in Peromyscus polionotus. Evolution 50:21872200

Leroy, G. 2014. Inbreeding depression in livestock species: review and meta-analysis. Anim. Genet. 45:618-628.

Leroy, G., T. Mary-Huard, E. Verrier, S. Danvy, E. Charvolin, and C. Danchin-Burge. 2013. Methods to estimate effective population size using pedigree data: Examples in dog, sheep, cattle and horse. Genet. Sel. Evol. 45:1.

Leutenegger, A.-L., B. Prum, E. Génin, C. Verny, A. Lemainque, F. Clerget-Darpoux, and E. A. Thompson. 2003. Estimation of the inbreeding coefficient through use of genomic data. Am. J. Hum. Genet. 73:516-523.

Liu, H., T. H. E. Meuwissen, A. C. Sørensen, and P. Berg. 2015. Upweighting rare favourable alleles increases long-term genetic gain in genomic selection programs. Genet. Sel. Evol. 47:19. https:// doi.org/10.1186/s12711-015-0101-0.

Liu, H., A. C. Sørensen, T. H. E. Meuwissen, and P. Berg. 2014. Allele frequency changes due to hitch-hiking in genomic selection programs. Genet. Sel. Evol. 46:8.

Lopes, M. S., J. W. M. Bastiaansen, L. Janss, E. F. Knol, and H. Bovenhuis. 2016. Genomic prediction of growth in pigs based on a model including additive and dominance effects. J. Anim. Breed. Genet. 133:180-186.

Luikart, G., N. Ryman, D. A. Tallmon, M. K. Schwartz, and F. W Allendorf. 2010. Estimation of census and effective population sizes: the increasing usefulness of DNA-based approaches. Conserv. Genet. 11:355-373.

Lynch, M., and B. Walsh. 1998. Genetics and Analysis of Quantitative Traits. Sinauer, Sunderland, MA.

Ma, L., J. R. O'Connell, P. M. VanRaden, B. Shen, A. Padhi, C. Sun, D. M. Bickhart, J. B. Cole, D. J. Null, G. E. Liu, Y. Da, and G. R. Wiggans. 2015. Cattle sex-specific recombination and genetic control from a large pedigree analysis. PLoS Genet. 11:e1005387. https://doi.org/10.1371/journal.pgen.1005387.

MacArthur, D. G., S. Balasubramanian, A. Frankish, N. Huang, J. Morris, K. Walter, L. Jostins, L. Habegger, J. K. Pickrell, S. B. Montgomery, C. A. Albers, Z. D. Zhang, D. F. Conrad, G. Lunter, H. Zheng, Q. Ayub, M. A. DePristo, E. Banks, M. Hu, R. E. Handsaker, J. A. Rosenfeld, M. Fromer, M. Jin, X. J. Mu, E Khurana, K. Ye, M. Kay, G. I. Saunders, M.-M. Suner, T. Hunt, I. H. A. Barnes, C. Amid, D. R. Carvalho-Silva, A. H. Bignell, C. Snow, B. Yngvadottir, S. Bumpstead, D. N. Cooper, Y. Xue, I. G. Romero, 1000 Genomes Project Consortium, J. Wang, Y. Li, R. A. Gibbs, S. A. McCarroll, E. T. Dermitzakis, J. K. Pritchard, J. C. Barrett, J. Harrow, M. E. Hurles, M. B. Gerstein, and C. Tyler-Smith. 2012. A systematic survey of loss-of-function variants in human protein-coding genes. Science 335:823-828. https://doi. org/10.1126/science.1215040.

MacLeod, I. M., T. H. E. Meuwissen, B. J. Hayes, and M. E. Goddard. 2009. A novel predictor of multilocus haplotype homozy- 
gosity: comparison with existing predictors. Genet. Res. (Camb.) 91:413-426.

Malécot, G. 1948. Les Mathématiques de L'hérédité. Masson, Paris, France.

Mc Parland, S., F. Kearney, and D. P. Berry. 2009. Purging of inbreeding depression within the Irish Holstein-Friesian population. Genet. Sel. Evol. 41:16.

Meuwissen, T. H. E. 1997. Maximizing the response of selection with a predefined rate of inbreeding. J. Anim. Sci. 75:934-940.

Meuwissen, T. H. E. 2009. Genetic management of small populations: A review. Acta Agric Scand. A Anim. Sci. 59:71-79.

Meuwissen, T. H. E., B. J. Hayes, and M. E. Goddard. 2001. Prediction of total genetic value using genome-wide dense marker maps. Genetics 157:1819-1829.

Meuwissen, T. H. E., and Z. Luo. 1992. Computing inbreeding coefficients in large populations. Genet. Sel. Evol. 24:305-313.

Meuwissen, T. H. E., and J. A. Woolliams. 1994. Effective sizes of livestock populations to prevent a decline in fitness. Theor. Appl. Genet. 89:1019-1026.

Miglior, F., and L. Beavers. 2014. Genetic Diversity and Inbreeding: Before and after Genomics. Accessed Jan. 3, 2017. http://www. progressivedairy.com/dairy-basics/ai-and-breeding/12422-geneticdiversity-and-inbreeding-before-and-after-genomics.

Miglior, F., E. B. Burnside, and W. D. Hohenboken. 1994. Heterogeneity amoung families of Holstein cattle in inbreeding depression for production traits. Pages 479-482 in Proc. 5th World Congr. Genet. Appl. Livest. Prod., Guelph, Canada. Vol. 18.

Miglior, F., E. B. Burnside, and B. W. Kennedy. 1995. Production traits of Holstein cattle: Estimation of nonadditive genetic variance components and inbreeding depression. J. Dairy Sci. 78:1174-1180.

Misztal, I., L. Varona, M. S. Culbertson, J. K. Bertrand, J. W. Mabry, T. J. Lawlor, C. P. Van Tassell, and N. Gengler. 1998. Studies on the value of incorporating the effect of dominance in genetic evaluations of dairy cattle, beef cattle and swine. Biotechnol. Agron. Soc. Environ. 2:227-233.

Nicholas, F. W., and C. Smith. 1983. Increased rates of genetic change in dairy cattle by embryo transfer and splitting. Anim. Sci. 36:341353.

Pedersen, L. D., A. C. Sørensen, and P. Berg. 2010. Marker-assisted selection reduces expected inbreeding but can result in large effects of hitchhiking. J. Anim. Breed. Genet. 127:189-198.

Ponsart, C., D. Le Bourhis, H. Knijn, S. Fritz, C. Guyader-Joly, T. Otter, S. Lacaze, F. Charreaux, L. Schibler, D. Dupassieux, and E. Mullaart. 2013. Reproductive technologies and genomic selection in dairy cattle. Reprod. Fertil. Dev. 26:12-21. https://doi. org/10.1071/RD13328

Pryce, J. E., M. Haile-Mariam, M. E. Goddard, and B. J. Hayes. 2014. Identification of genomic regions associated with inbreeding depression in Holstein and Jersey dairy cattle. Genet. Sel. Evol. 46:71.

Pryce, J. E., B. J. Hayes, and M. E. Goddard. 2012. Novel strategies to minimize progeny inbreeding while maximizing genetic gain using genomic information. J. Dairy Sci. 95:377-388.

Purfield, D. C., D. P. Berry, S. McParland, and D. G. Bradley. 2012 Runs of homozygosity and population history in cattle. BMC Genet. 13:70.

Robertson, A. 2007. Inbreeding in artificial selection programmes. Genet. Res. 89:275-280.

Rodríguez-Ramilo, S. T., L. A. García-Cortés, and M. Á. R. de Cara. 2015. Artificial selection with traditional or genomic relationships: consequences in coancestry and genetic diversity. Front. Genet. $6: 127$

Roughsedge, T., R. Pong-Wong, J. A. Woolliams, and B. Villanueva. 2008. Restricting coancestry and inbreeding at a specific position on the genome by using optimized selection. Genet. Res. (Camb.) 90:199-208.

Sahana, G., U. S. Nielsen, G. P. Aamand, M. S. Lund, and B. Guldbrandtsen. 2013. Novel harmful recessive haplotypes identified for fertility traits in Nordic Holstein cattle. PLoS One 8:e82909. https://doi.org/10.1371/journal.pone.0082909.
Saura, M., A. Fernández, L. Varona, A. I. Fernández, M. Á. R. de Cara, C. Barragán, and B. Villanueva. 2015. Detecting inbreeding depression for reproductive traits in Iberian pigs using genomewide data. Genet. Sel. Evol. 47:1.

Segelke, D., H. Taubert, S. Jansen, H. Pausch, F. Reinhardt, and G. Thaller. 2014. Management of genetic characteristics. Interbull 48:85-88.

Sewalem, A., G. J. Kistemaker, F. Miglior, and B. J. Van Doormaal. 2006. Analysis of inbreeding and its relationship with functional longevity in Canadian dairy cattle. J. Dairy Sci. 89:2210-2216.

Shanks, R. D., and J. L. Robinson. 1989. Embryonic mortality attributed to inherited deficiency of uridine monophosphate synthase. J. Dairy Sci. 72:3035-3039. https://doi.org/10.3168/jds.S00220302(89)79456-X

Shuster, D. E., M. E. Kehrli, M. R. Ackermann, and R. O. Gilbert. 1992. Identification and prevalence of a genetic defect that causes leukocyte adhesion deficiency in Holstein cattle. Proc. Natl. Acad. Sci. USA 89:9225-9229.

Smith, J. M., and J. Haigh. 1974. The hitch-hiking effect of a favourable gene. Genet. Res. 23:23-35.

Smith, L. A., B. G. Cassell, and R. E. Pearson. 1998. The effects of inbreeding on the lifetime performance of dairy cattle. J. Dairy Sci. 81:2729-2737. https://doi.org/10.3168/jds.S0022-0302(98)758308.

Sonesson, A. K., J. A. Woolliams, and T. H. E. Meuwissen. 2012. Genomic selection requires genomic control of inbreeding. Genet. Sel. Evol. 44:27.

Sørensen, A. C., M. K. Sorensen, and P. Berg. 2005. Inbreeding in Danish dairy cattle breeds. J. Dairy Sci. 88:1865-1872.

Soule, M. E. 1980. Thresholds for survival: maintaining fitness and evolutionary potential. Pages 151-169 in Conservation Biology: An Evolutionary-Ecological Perspective. Sinauer, Sunderland, MA.

Stachowicz, K., M. Sargolzaei, F. Miglior, and F. S. Schenkel. 2011. Rates of inbreeding and genetic diversity in Canadian Holstein and Jersey cattle. J. Dairy Sci. 94:5160-5175.

Stam, P. 1980. The distribution of the fraction of the genome identical by descent in finite random mating populations. Genet. Res. 35:131-155.

$\mathrm{Su}$, G., O. F. Christensen, T. Ostersen, M. Henryon, and M. S. Lund. 2012. Estimating additive and non-additive genetic variances and predicting genetic merits using genome-wide dense single nucleotide polymorphism markers. PLoS One 7:e45293.

Sun, C., and P. M. VanRaden. 2014. Increasing long-term response by selecting for favorable minor alleles. PLoS One 9:e88510. https:// doi.org/10.1371/journal.pone.0088510.

Sun, C., P. M. VanRaden, J. B. Cole, and J. R. O'Connell. 2014. Improvement of prediction ability for genomic selection of dairy cattle by including dominance effects. PLoS One 9:e103934.

Sun, C., P. M. VanRaden, J. R. O'Connell, K. A. Weigel, and D. Gianola. 2013. Mating programs including genomic relationships and dominance effects. J. Dairy Sci. 96:8014-8023.

Szpiech, Z. A., J. Xu, T. J. Pemberton, W. Peng, S. Zöllner, N. A. Rosenberg, and J. Z. Li. 2013. Long runs of homozygosity are enriched for deleterious variation. Am. J. Hum. Genet. 93:90-102.

Taberlet, P., A. Valentini, H. R. Rezaei, S. Naderi, F. Pompanon, R. Negrini, and P. Ajmone-Marsan. 2008. Are cattle, sheep, and goats endangered species? Mol. Ecol. 17:275-284.

Thompson, J. R., R. W. Everett, and N. L. Hammerschmidt. 2000a. Effects of inbreeding on production and survival in Holsteins. J. Dairy Sci. 83:1856-1864

Thompson, J. R., R. W. Everett, and C. W. Wolfe. 2000b. Effects of inbreeding on production and survival in Jerseys. J. Dairy Sci. 83:2131-2138.

Tiezzi, F., and C. Maltecca. 2015. Accounting for trait architecture in genomic predictions of US Holstein cattle using a weighted realized relationship matrix. Genet. Sel. Evol. 47:24.

Toro, M. A., B. Nieto, and C. Salgado. 1988. A note on minimization of inbreeding in small-scale selection programmes. Livest. Prod. Sci. 20:317-323.

Toro, M. A., and L. Varona. 2010. A note on mate allocation for dominance handling in genomic selection. Genet. Sel. Evol. 42:33. 
Van Eenennaam, A. L., and B. P. Kinghorn. 2014. Use of mate selection software to manage lethal recessive conditions in livestock populations. In Proc. 10th World Congr. Genet. Appl. Livest. Prod.

VanRaden, P. M. 2008. Efficient methods to compute genomic predictions. J. Dairy Sci. 91:4414-4423.

VanRaden, P. M., T. J. Lawlor, T. H. Short, and I. Hoeschele. 1992. Use of reproductive technology to estimate variances and predict effects of gene interactions. J. Dairy Sci. 75:2892-2901.

VanRaden, P. M., and R. H. Miller. 2006. Effects of nonadditive genetic interactions, inbreeding, and recessive defects on embryo and fetal loss by seventy days. J. Dairy Sci. 89:2716-2721. https://doi. org/10.3168/jds.S0022-0302(06)72347-5.

VanRaden, P. M., K. M. Olson, D. J. Null, and J. L. Hutchison. 2011a Harmful recessive effects on fertility detected by absence of homozygous haplotypes. J. Dairy Sci. 94:6153-6161. https://doi. org/10.3168/jds.2011-4624.

VanRaden, P. M., K. M. Olson, G. R. Wiggans, J. B. Cole, and M E. Tooker. 2011b. Genomic inbreeding and relationships among Holsteins, Jerseys, and Brown Swiss. J. Dairy Sci. 94:5673-5682.

VanRaden, P. M., and L. A. Smith. 1999. Selection and mating considering expected inbreeding of future progeny. J. Dairy Sci. 82:27712778. https://doi.org/10.3168/jds.S0022-0302(99)75534-7.

Verrier, E., J. J. Colleau, and J. L. Foulley. 1993. Long-term effects of selection based on the animal model BLUP in a finite population. Theor. Appl. Genet. 87:446-454.

Wall, E., S. Brotherstone, J. F. Kearney, J. A. Woolliams, and M. P. Coffey. 2005. Impact of nonadditive genetic effects in the estimation of breeding values for fertility and correlated traits. J. Dairy Sci. 88:376-385.

Wang, C., Z. Xu, G. Jin, Z. Hu, J. Dai, H. Ma, Y. Jiang, L. Hu, M. Chu, S. Cao, and H. Shen. 2013. Genome-wide analysis of runs of homozygosity identifies new susceptibility regions of lung cancer in Han Chinese. J. Biomed. Res. 27:208-214. https://doi. org/10.7555/JBR.27.20130017.

Weigel, K. A., and S. W. Lin. 2000. Use of computerized mate selection programs to control inbreeding of Holstein and Jersey cattle in the next generation. J. Dairy Sci. 83:822-828.

Weir, B. S. 2008. Linkage disequilibrium and association mapping. Annu. Rev. Genomics Hum. Genet. 9:129-142.

Wellmann, R., and J. Bennewitz. 2011. The contribution of dominance to the understanding of quantitative genetic variation. Genet. Res. (Camb.) 93:139-154. https://doi.org/10.1017/S0016672310000649.
Wellmann, R., and J. Bennewitz. 2012. Bayesian models with dominance effects for genomic evaluation of quantitative traits. Genet. Res. (Camb.) 94:21-37.

Wiggans, G. R., T. A. Cooper, P. M. Vanraden, K. M. Olson, and M. E. Tooker. 2012. Use of the Illumina Bovine3K BeadChip in dairy genomic evaluation. J. Dairy Sci. 95:1552-1558. https://doi. org/10.3168/jds.2011-4985.

Wray, N. R., and M. E. Goddard. 1994. Increasing long-term response to selection. Genet. Sel. Evol. 26:1-21.

Wright, S. 1922. Coefficients of inbreeding and relationship. Am. Nat. $56: 330-338$.

Wright, S. 1931. Evolution in Mendelian populations. Genetics 16:97159.

Xiang, T., O. F. Christensen, Z. G. Vitezica, and A. Legarra. 2016. Genomic evaluation by including dominance effects and inbreeding depression for purebred and crossbred performance with an application in pigs. Genet. Sel. Evol. 48:92. https://doi.org/10.1186/ s12711-016-0271-4.

Yang, J., B. Benyamin, B. P. McEvoy, S. Gordon, A. K. Henders, D R. Nyholt, P. A. Madden, A. C. Heath, N. G. Martin, G. W. Montgomery, M. E. Goddard, and P. M. Visscher. 2010. Common SNPs explain a large proportion of the heritability for human height. Nat. Genet. 42:565-569.

Zhang, Q., B. Guldbrandtsen, M. Bosse, M. S. Lund, and G. Sahana 2015. Runs of homozygosity and distribution of functional variants in the cattle genome. BMC Genomics 16:542.

Zhang, Q., B. Guldbrandtsen, M. P. Calus, M. S. Lund, and G. Sahana. 2016. Comparison of gene-based rare variant association mapping methods for quantitative traits in a bovine population with complex familial relationships. Genet. Sel. Evol. 48:60. https:/ doi.org/10.1186/s12711-016-0238-5.

Zhang, Z., J. Liu, X. Ding, P. Bijma, D.-J. de Koning, and Q. Zhang. 2010. Best linear unbiased prediction of genomic breeding values using a trait-specific marker-derived relationship matrix. PLoS One 5:12648.

Zhu, Z., A. Bakshi, A. A. E. Vinkhuyzen, G. Hemani, S. H. Lee, I. M. Nolte, J.V. van Vliet-Ostaptchouk, H. Snieder, LifeLines Cohort Study, T. Esko, L. Milani, R. Mägi, A. Metspalu, W. G. Hill, B. S. Weir, M. E. Goddard, P. M. Visscher, and J. Yang. 2015. Dominance genetic variation contributes little to the missing heritability for human complex traits. Am. J. Hum. Genet. 96:377-385. 